International Journal of Physical Sciences and Engineering
Available online at http://sciencescholar.us/journal/index.php/ijpse
Vol. 2 No. 3, December 2018, pages: $29 \sim 35$
e-ISSN : 2550-6943, p-ISSN : 2550-6951
https://doi.org/10.29332/ijpse.v2n3.180

\title{
Digital Measuring Equipment of Meat Water Connection with Copper Electrode Sensor Based on Microcontroller AT89S52
}

\author{
I Wayan Supardi a, I Made Satriya Wibawa b , I Gede Angga Rimawan c, Arief Laksono d, Mahendy \\ Risnawati Kunthi e
}

Article history: Received 2 April 2018, Accepted: 1 September 2018, Published: 14 September 2018

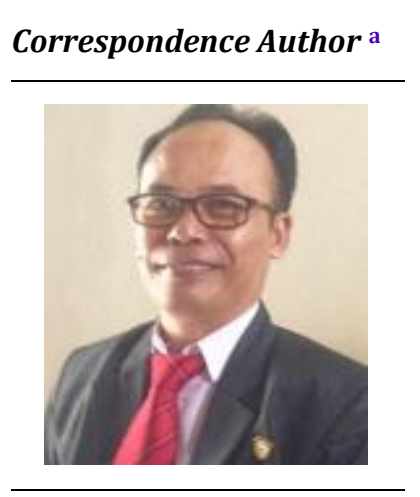

Keywords

$A D C$;

Electrode;

Meat water connection;

Microcontroller;

Sensor;

\begin{abstract}
Meat moisture measuring devices can be made using microcontroller AT89S52 based copper electrode sensors. The workflow of the meat content measuring device begins with a copper sensor that detects the level of pork water, the voltage generated by the sensor is passed to the ADC. The voltage received is then converted into digital data in the form of meat content data measured by microcontroller AT89S52. The digital data obtained was then processed by microcontroller AT89S52 and the water content of pork, beef, and chicken meat was displayed on LCD $2 \times 16$. The results obtained from three meat samples were pork meat samples of $99.995 \%$, beef samples of $99.994 \%$ and chicken meat samples of $99.994 \%$.
\end{abstract}

e-ISSN: 2550-6943, p-ISSN: 2550-6951 ${ }^{\circ}$ Copyright 2018. The Author. SS Journals Published by Universidad Técnica de Manabí. This is an open-access article under the CC BY-SA 4.0 license (https://creativecommons.org/licenses/by-sa/4.0/) All rights reserved.

\section{Contents}

Abstract

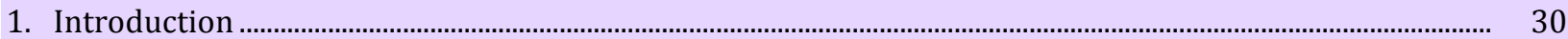

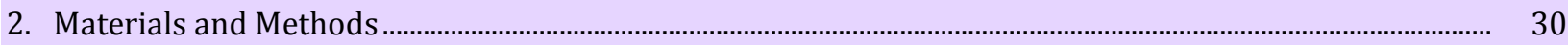

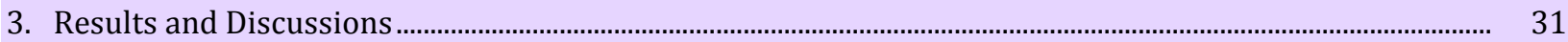

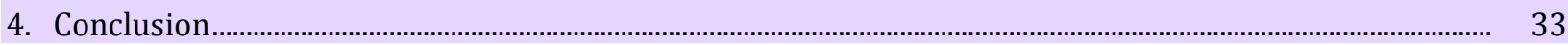

a Department of Physics, Udayana University, Bali, Indonesia

b Department of Physics, Udayana University, Bali, Indonesia

c Department of Physics, Udayana University, Bali, Indonesia

d Department of Physics, Udayana University, Bali, Indonesia

e Department of Physics, Udayana University, Bali, Indonesia 


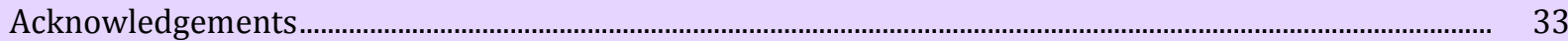

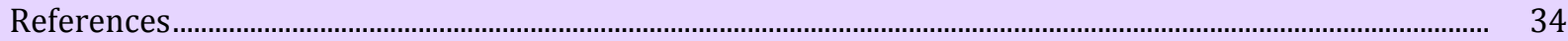

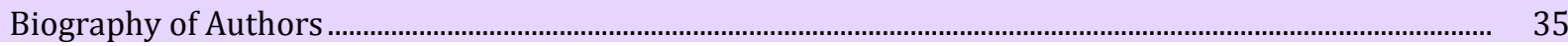

\section{Introduction}

Many methods have been carried out to determine the quality of meat such as Electronic Nose Based Metal Oxide Semiconductor Sensors as an Alternative Technique for Red Meat Piracy Classification (Barbri, 2008), measurement of all salting meat (Breijo, 2008), Meat water content meter using copper electrode sensor based on AT89S52 microcontroller (Rimawan, 2018), (Saffle, 1958) measurements made only on the water content of pork, all of these results are semi-digital, still need to be processed in the laboratory, and only limited to one of the contents of meat. But the tools made can be used directly (mobile) and can measure the moisture content of chicken, pork, and beef so that measurements can be made more effectively and efficiently (Forrest, et al.: 1975).

\section{Materials and Methods}

Testing the physical quality of meat can be done by measuring the water holding capacity (WHC) through a procedure that is measuring the binding capacity of meat water using a "Clement 2000" centrifuge. The implementation is as follows: $10 \mathrm{~g}$ of meat is ground with a blender then weighed with Sartorius scales so that the initial weight is obtained. Next, the meat is wrapped in duplicate "Whatman 41" filter paper, then the meat package is put into a centrifuge and centrifuged at $3000 \mathrm{rpm}$ for 30 minutes (Lawrie, et al.: 1995, 2006). Samples that have been messed up are then weighed without filter paper to obtain the final weight. The percentage of WHC is calculated according to Soeparno (2009) with the formula:

$\% \mathrm{WHC}=[($ initial water weight - final water weight $) /($ initial water weight $)] \times 100 \%$

The overall hardware design of the meat content measuring instrument is shown in Figure 4.2. This circuit consists of a series of copper electrode sensors, ADC0804 circuit, minimum system circuit, AT89S52 microcontroller and 2x16 LCD circuit as shown in Figure1.

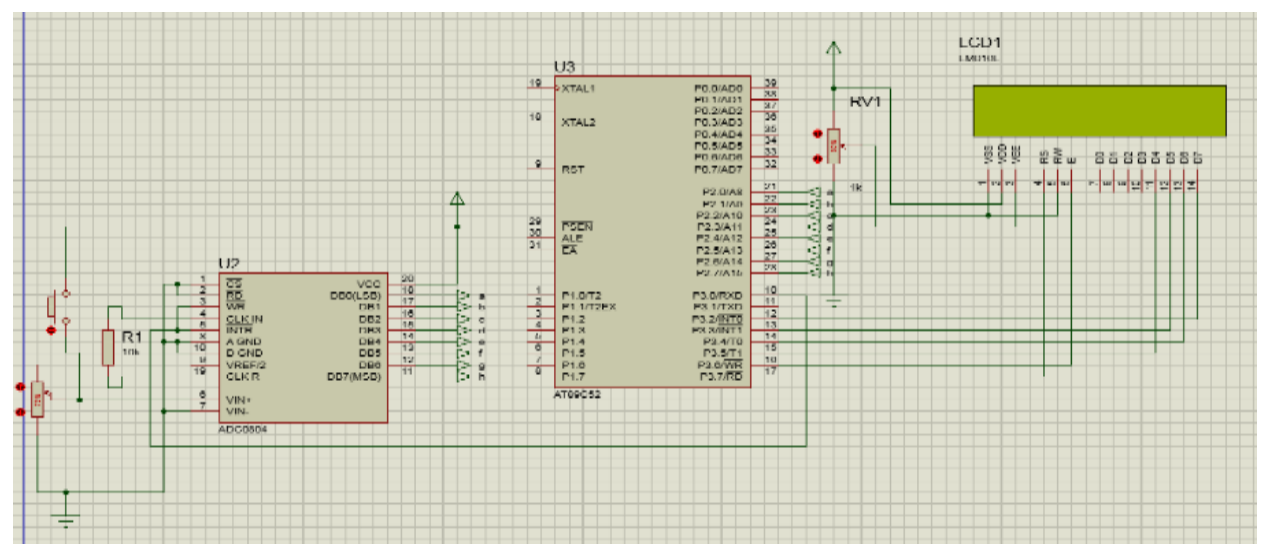

Figure 1. Series of meat moisture devices with AT89S52 microcontroller based copper electrode sensors 


\section{Results and Discussions}

The design results from the tools obtained from this study are as shown in Figure 2.

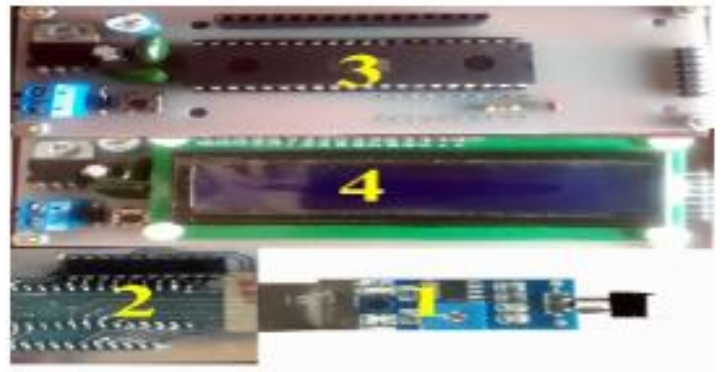

Figure 2. Meat moisture measuring instrument with AT89S52 microcontroller based copper electrode sensor

The function of each part of the tool as shown in Figure 2 is as follows:

a) Copper electrode sensor functions as sensing the moisture content of meat.

b) The ADC0804 circuit serves as a modifier of the sensor output voltage in the form of analog data into digital data.

c) The minimum system circuit AT89S52 serves as a data processor of the copper electrode sensor output voltage in the form of digital data into data on meat content in percentage units (\%).

d) 2x16 LCD circuit functions as a regulator of data that has been processed to be displayed on the LCD.

The signal response path starts from the copper electrode sensor circuit by changing the level of the detected meat to a sensor output voltage. The resulting sensor output voltage is connected to the Vin (+) ADC pin. The reading result of the $\mathrm{ADC}$ is then converted to digital data. After the conversion process is complete and digital data has been obtained, the results are sent to the AT89S52 microcontroller. Digital data that has been read by the microcontroller is then processed into digital data forming a numeric display on the 2x16 LCD. Data conversion and processing are arranged by the program downloaded on the AT89S52 microcontroller. After the digital data is processed, then it is sent to the LCD to be displayed as meat content data measured by the design tool.

Testing of Design Tools with pork

The results of the Design Tool testing with pork are seen in table 1

Table 1

Data on the results of the test of pork moisture content

\begin{tabular}{ccc}
\hline No & $\begin{array}{c}\text { Measurement of Moisture (\%) } \\
\text { Comparison }\end{array}$ & Design \\
\hline 1 & 16,20 & 16,12 \\
& 16,36 & 16,52 \\
& 17,40 & 17,58 \\
& 19,56 & 19,69 \\
2 & 21,24 & 21,32 \\
& 23,45 & 23,33 \\
& 23,56 & 23,68 \\
& 24,89 & 24,90 \\
\hline
\end{tabular}

\begin{tabular}{ccc}
\hline \multirow{2}{*}{ No } & \multicolumn{2}{c}{ Measurement of Moisture (\%) } \\
\cline { 2 - 3 } & & \\
\hline 3 & 25,27 & 25,28 \\
& 25,78 & 25,76 \\
& 26,42 & 26,41 \\
& 26,51 & 26,12 \\
4 & 26,69 & 26,70 \\
& 56,78 & 56,88 \\
& 58,79 & 58,78 \\
\hline
\end{tabular}

Supardi, I. W., Wibawa, I. M. S., Rimawan, I. G. A., Laksono, A., \& Kunthi, M. R. (2018). Digital measuring equipment of meat water connection with copper electrode sensor based on microcontroller AT89S52. International Journal of Physical Sciences and Engineering, 2(3), 29-35. https://doi.org/10.29332/ijpse.v2n3.180 


\begin{tabular}{ll}
\hline 24,58 & 24,91 \\
24,95 & 24,96 \\
\hline
\end{tabular}

Regarding Table 1 can be made a graph as shown in figure 3.

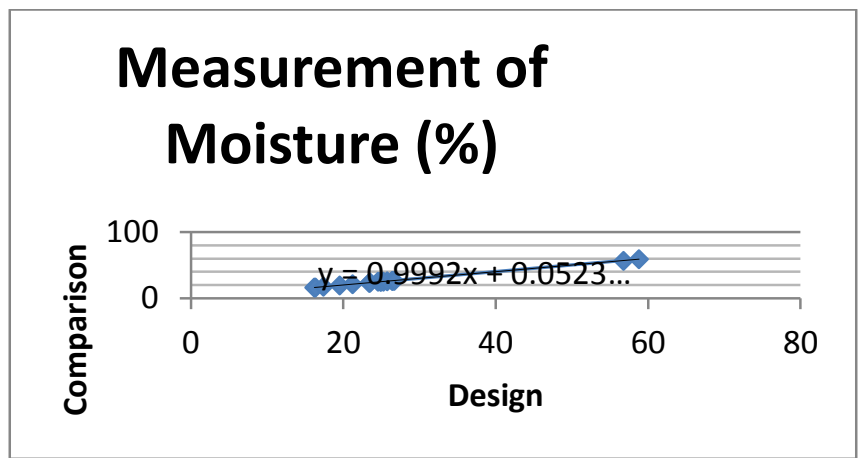

Figure 3. Linear chart of comparative test results and pork meat design tools

Figure 3 shows a graph of the linearity of the results of the average measurement of pork content by the design tool with the lab comparison method. The determination coefficient obtained from the analysis of the design tool testing data is equal to 0.99995 . The coefficient states that the suitability of the design tool with the comparison is $99.995 \%$. The discrepancy occurs due to the sensitivity of the sensor from the design tool.

Testing of Design Tools with chicken meat

Test Results of Design Tools with chicken meat as in table 2

Table 2

Data of test results for chicken meat moisture content

\begin{tabular}{ccc}
\hline \multirow{2}{*}{ No } & \multicolumn{3}{c}{ Measurement of Moisture $(\%)$} \\
\hline 1 & 12.2 & 12.12 \\
& 13.36 & 13.52 \\
& 15.4 & 15.58 \\
& 16.56 & 16.69 \\
2 & 18.24 & 18.32 \\
& 23.45 & 23.33 \\
& 23.56 & 23.68 \\
& 24.89 & 24.9 \\
3 & 24.58 & 24.91 \\
& 24.95 & 24.96 \\
& 25.27 & 25.28 \\
& 25.78 & 25.76 \\
& 26.42 & 26.41 \\
& 26.51 & 26.12 \\
\hline
\end{tabular}

\begin{tabular}{|c|c|c|}
\hline \multirow{2}{*}{ No } & \multicolumn{2}{|c|}{ Measurement of Moisture (\%) } \\
\hline & Comparison & Design \\
\hline \multirow[t]{5}{*}{4} & 56.78 & 56.88 \\
\hline & 58.79 & 58.78 \\
\hline & 62.34 & 62.15 \\
\hline & 67.87 & 67.46 \\
\hline & 69.89 & 69.88 \\
\hline \multirow[t]{5}{*}{5} & 70.23 & 70.34 \\
\hline & 71.45 & 71.34 \\
\hline & 73.76 & 73.36 \\
\hline & 74.46 & 74.6 \\
\hline & 75.89 & 75.45 \\
\hline
\end{tabular}

Regarding Table 2 can be made a graph as shown in figure 4 


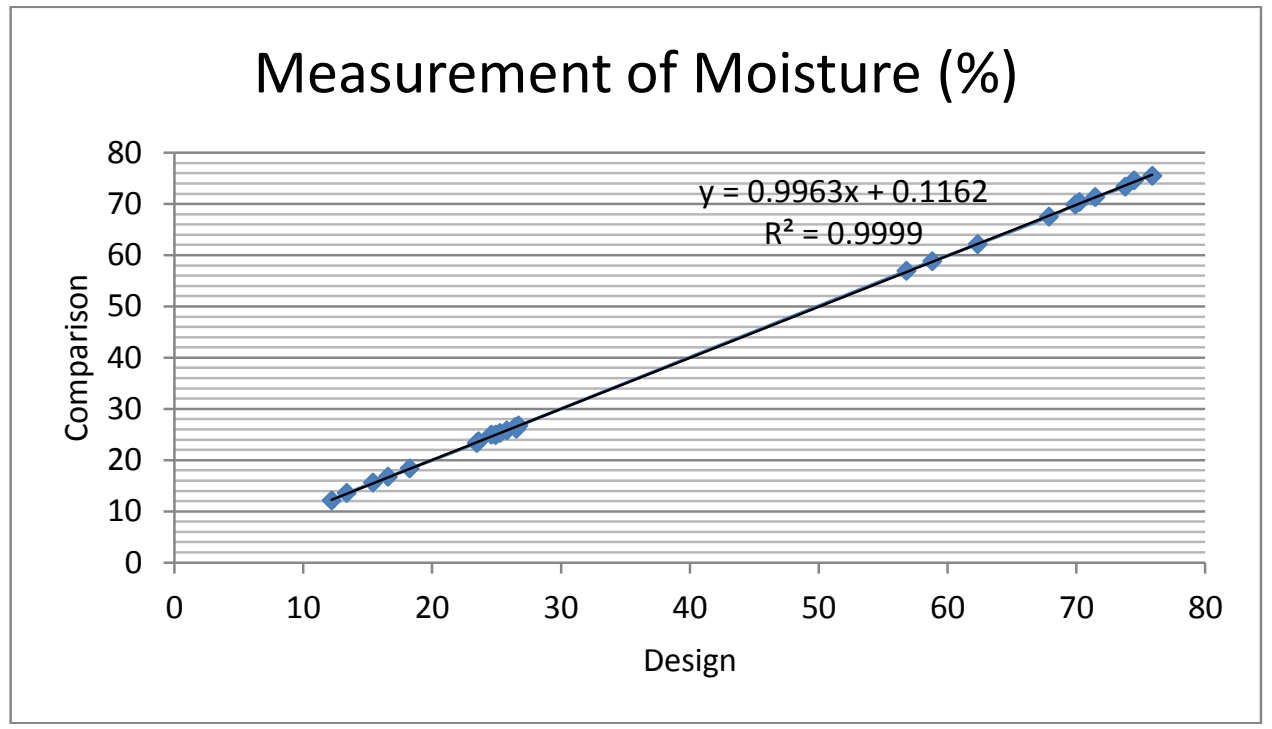

Figure 4. Chart of linearity of comparative testing results and chicken meat design tools

Figure 4 shows a graph of the linearity of the results of the average measurement of chicken meat content by the design tool with the lab comparison method. The determination coefficient (@) obtained from the analysis of the design tool testing data is equal to 0.99994 . The coefficient states that the suitability of the design tool with the comparison is $99.994 \%$. The discrepancy occurs due to the sensitivity of the sensor from the design tool.

\section{Conclusion}

The conclusions of this study are as follows: 1 . It can be made a measuring instrument for pork content using a copper electrode sensor based on AT89S52 microcontroller. 2. The workflow of the meat content measuring device begins with a copper sensor that determines the level of pork water, the voltage generated by the sensor is passed to the ADC. The voltage received is then converted into digital data in the form of meat content data measured by the AT89S52 microcontroller. The digital data obtained is then processed by the AT89S52 microcontroller and the water content of pork, beef and chicken is displayed on LCD $2 \times 16$. 3 . The results obtained from three meat samples, namely pork samples of $99.995 \%$, beef samples of $99.994 \%$ and chicken meat samples of $99.994 \%$.

\section{Acknowledgments}

Praise God, the writer offered the Presence of God Almighty because of His blessings and blessings the writer could complete this paper. On this occasion, we also did not forget to thank: Udayana University Chancellor as the fund holder, Udayana University Institute of Research and Community Service (LPPM) who provided the opportunity to carry out research, Dean of the Faculty of Mathematics and Natural Sciences, Udayana University, Physics Study Program, University Mathematics Faculty Udayana and Friends of the Physics Study Program Lecturer at Udayana University.

Supardi, I. W., Wibawa, I. M. S., Rimawan, I. G. A., Laksono, A., \& Kunthi, M. R. (2018). Digital measuring equipment of meat water connection with copper electrode sensor based on microcontroller AT89S52. International Journal of Physical Sciences and Engineering, 2(3), 29-35. https://doi.org/10.29332/ijpse.v2n3.180 


\section{References}

El Barbri, N., Llobet, E., El Bari, N., Correig, X., \& Bouchikhi, B. (2008). Electronic nose based on metal oxide semiconductor sensors as an alternative technique for the spoilage classification of red meat. Sensors, $8(1)$, 142-156.

Forrest, J. C., Aberle, E. D., Hedrick, H. B., Judge, M. D., \& Merkel, R. A. (1975). Principles of meat science. WH Freeman and Co.

García-Breijo, E., Barat, J. M., Torres, O. L., Grau, R., Gil, L., Ibanez, J., ... \& Fraile, R. (2008). Development of a puncture electronic device for electrical conductivity measurements throughout meat salting. Sensors and Actuators A: Physical, 148(1), 63-67.

Lawrie, R. A. (1995). Ilmu Daging. Terjemahan: A. Parakkasi.

Lawrie, R. A., \& Ledward, D. A. (2006). The structure and growth of muscle: Lawrie's meat science.

Rimawan, I. G. A., Supardi, I. W., \& Astawa, I. P. A. (2018). Meat water content meter using copper electrode sensor based on AT89S52 microcontroller. International Research Journal of Engineering, IT and Scientific Research, 4(5), 1-6.

Saffle, R. L. (1958). The effect of fatness on some processing and palatability characteristics of pork carcasses. Michigan State College of Agriculture and Applied Science. Department of Animal Husbandry.

Soeparno. (2009. Ilmu dan Teknologi Daging. Cetakan kelima, Yogyakarta : Gadjah Mada University Press. 


\section{Biography of Authors}

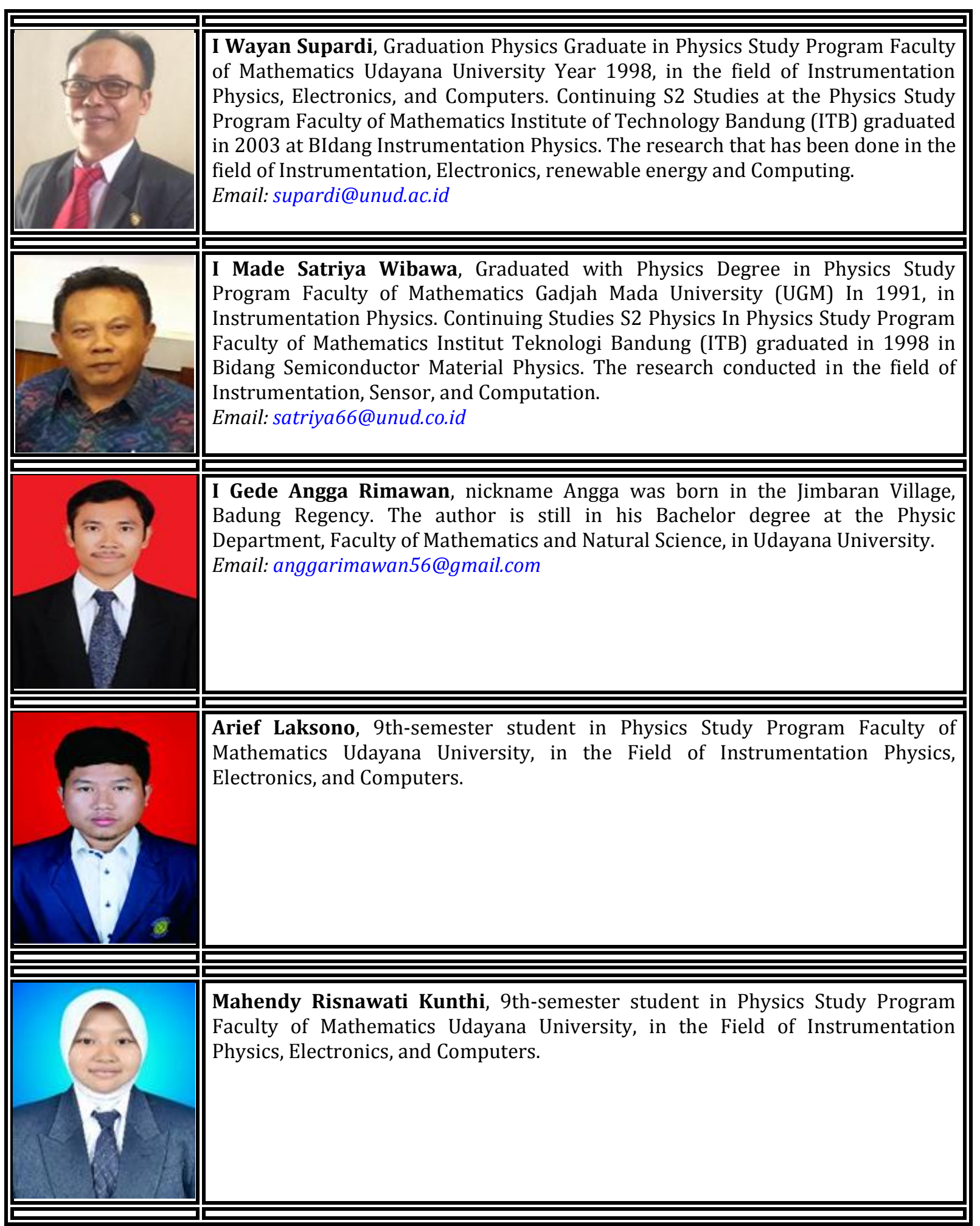

Supardi, I. W., Wibawa, I. M. S., Rimawan, I. G. A., Laksono, A., \& Kunthi, M. R. (2018). Digital measuring equipment of meat water connection with copper electrode sensor based on microcontroller AT89S52. International Journal of Physical Sciences and Engineering, 2(3), 29-35. https://doi.org/10.29332/ijpse.v2n3.180 